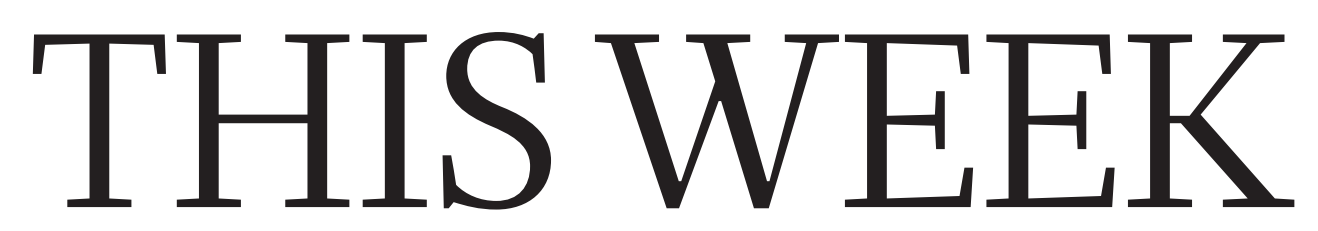

EDITORIALS

INGENIUM Colin Macilwain on why engineers don't fix lawnmowers $\mathbf{p . 8 8 5}$
SIGNATURE TUNE

Musical hands play

on and on $\mathbf{p . 8 8 7}$

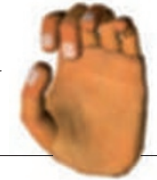

PLANET Has new discovery Gliese $581 \mathrm{~g}$ vanished from the skies? p.889

\title{
The balance of probabilities
}

\section{IPCC members last week considered the best way to quantify uncertainty. They are not alone in needing to do so - the media must also take a firm line when it comes to scientific reporting.}

W hat do the British Broadcasting Corporation (BBC), the Intergovernmental Panel on Climate Change (IPCC) and the Central Intelligence Agency (CIA) have in common? All have given serious consideration to how to communicate uncertainty. In March 1951, the CIA secretly warned US officials that there was a "serious possibility" that the Soviet Union would invade Yugoslavia. Sherman Kent, a CIA intelligence analyst, was dismayed to discover that nobody seemed to agree on what that meant. Whereas some understood there to be a $20 \%$ chance that the Soviets would invade, others put the risk as high as $80 \%$. So began the CIA's efforts to brief with more precise language, which Kent labelled 'words of estimative probability'. Out went 'possibility' - serious or otherwise - and in came an uncertainty scale from 'almost certain' to 'almost certainly not'.

The IPCC also likes words of estimative probability, which are based on a numerical assessment of the likelihood they represent. Recent global warming was famously described in its 2007 report as "very likely" driven by human activity, corresponding to a more than $90 \%$ chance of being true. At its annual meeting in Busan, South Korea, last week, the IPCC was right to acknowledge criticism from the InterAcademy Council (IAC) that handling of uncertainty by its three separate working groups was inconsistent. But it is not clear whether the IAC's suggested solution - that the panel adopt more widely the qualitative statements, such as "high agreement, much evidence", used by the social scientists in Working Group III — will offer a better option for the more robust findings of the physical scientists. Much evidence sounds as open to interpretation as the CIA's serious possibility. The IPCC should ensure that, where possible, it retains quantitative probability scales. More important still is not to isolate these numbers from the equivalent probabilistic terms, such as very likely, which studies show are often ineffective at representing the intended degree of certainty.

Separate draft guidance notes on the treatment of uncertainty, presented in Busan by IPCC working group co-chairs, suggest that, where evidence and understanding are overwhelming, IPCC authors could jettison uncertainty qualifiers altogether and present research findings as statement of fact. They should proceed with extreme caution. In a politically charged policy area, such interpretation is better done by policy-makers and society at large. To emphasize a remote possibility is probably a better strategy for scientists than to gloss over it altogether.

There is more to communication of uncertainty than tone and content - the audience must also be considered, which brings us to the BBC. Like the IPCC, the BBC is an easy target for critics, who leap on claimed examples of bias and errors of judgement. And, like the IPCC, the BBC has launched a review of its procedures, in its case, the impartiality and accuracy of its science coverage. All radio, television and online content is under scrutiny, but it seems likely that the review will address news coverage in particular, and, within that, climate change. (BBC insiders think that complaints from climate sceptics prompted the review.)

The terms of reference for the review define science as "statements,

research findings or other claims made by scientists". In reality, perhaps the most common complaint from scientists about the corporation's coverage of global warming is the exposure handed to sceptical non-scientists, such as former UK chancellor Nigel Lawson. This is the source of the long-standing 'false balance' problem. The BBC Trust, which is running the review, should take a stricter line here. If $\mathrm{BBC}$ staff want to use non-experts to criticize widely accepted science, they must explain this lack of expertise to the audience, and why the BBC has invited them

It is not a lack of scientific understanding that produces poor science content.

This is why the signal of the climate-science story, the steady accumulation of evidence that points in the same direction, is too easily drowned out by the noise - criticism and hype of individual papers, statements from high-profile individuals and spurious dissent. Against that background, the uncertainty of climate science becomes a story in itself, not a crucial footnote to the main narrative.

This does not leave researchers who deal with the media impotent when they want to communicate uncertainty. They should learn from Kent and the IPCC, and use more precise language. Kent identified 'weasel words', such as 'could', 'suggest' and 'may', that were best avoided because they were "expressions with sound but upon reflection almost without meaning". These are not words of science, but of the news media. The world is an uncertain place, but scientific findings can be virtually certain, likely, improbable or highly doubtful. Take your pick. .

\section{Save our cities}

\section{Scientists researching problems such as water management should focus more on urban areas.}

$\mathrm{S}$ cientists are city people. More than one-tenth of the workforce in the Washington DC metropolitan area are scientists and engineers. Beijing has more than 160,000 professionals in research and development. Worldwide, resources such as universities and researchers are concentrated in urban areas. So why do so many scientists ignore the needs of our cities? It is time to encourage scientists and universities to pay more attention to urban areas, and Nature this week includes a package of articles about researchers and cities (see page 899). 